\title{
On the Efficiency of the Multi-Channel Analysis of Surface Wave Method for Shallow and Semideep Loose Soil Layers
}

\author{
Kasgin Khaheshi Banab ${ }^{1}$ and Dariush Motazedian ${ }^{2}$ \\ ${ }^{1}$ Department of Civil and Environmental Engineering, Carleton University, Room 2140, Herzberg Bldg., \\ 1125 Colonel By Drive, Ottawa, ON, Canada K1S 5B6 \\ 2 Department of Earth Science, Room 2140, Herzberg Bldg., 1125 Colonel By Drive, Ottawa, ON, Canada K1S 5B6
}

Correspondence should be addressed to Kasgin Khaheshi Banab, kkbanab@connect.carleton.ca

Received 5 August 2009; Revised 13 April 2010; Accepted 10 May 2010

Academic Editor: Yun-tai Chen

Copyright $\odot 2010$ K. Khaheshi Banab and D. Motazedian. This is an open access article distributed under the Creative Commons Attribution License, which permits unrestricted use, distribution, and reproduction in any medium, provided the original work is properly cited.

The multi-channel analysis of surface waves (MASWs) method was used to obtain the shear wave velocity variations through near surface $($ depth $<30 \mathrm{~m})$ and semideep $(30 \mathrm{~m}<$ depth $<100 \mathrm{~m})$ soil layers in the city of Ottawa, Canada. Sixteen sites were examined to evaluate the capability of the active and passive MASW methods for cases where the shear wave velocity $\left(V_{s}\right)$ contrast between very loose soil $\left(V_{s}<200 \mathrm{~m} / \mathrm{s}\right)$ and very firm bedrock $\left(V_{s}>2,300 \mathrm{~m} / \mathrm{s}\right)$ is very large. The MASW velocity results compared with those of other geophysical approaches, such as seismic reflection/refraction methods and borehole data, where available, mostly confirming the capability of the MASW method to distinguish the high shear wave velocity contrast in the study area. We have found that, of the inversion procedures of MASW data, the random search inversion technique provides better results than the analytical generalized inversion method.

\section{Introduction}

The city of Ottawa is located in the active Western Quebec seismic zone (Adams and Halchuck [1]), which extends from Montreal, Quebec to Ottawa, Ontario, Canada. With the new requirements in the National Building Code of Canada (NBC, 2005 [2]), seismic soil classifications have become an important issue for major Canadian cities, including Ottawa. In order to carry out the seismic microzonation measurements, a working group on seismic hazard microzonation in the Ottawa area was established based on a collaboration of Carleton University and the Geological Survey of Canada (GSC). This research group aims to obtain shear velocitydepth $\left(S\right.$-wave or $\left.V_{s}\right)$ functions and the thickness weighted average shear wave velocity for the top 30 meters, following the U.S. National Earthquake Hazards Reduction Program (NEHRP) site classification as recommended by National Building Code of Canada (NBCC, 2005 [2]).

In order to provide a reliable shear wave velocitydepth function unique to the study area, several methods including seismic refraction/reflection, multi-channel anal- ysis of surface waves (MASWs), spectral ratio methods, and borehole measurements have been applied in the microzonation measurements. As shown in Figure 1, the refraction/reflection method (black solid circles) has been applied to more than half of the study area while other methods have been applied in smaller portions of the city. The application of different methods is needed, since each method provides some valuable information on the different parameters involved in seismic soil amplification. In the current paper, the application, results, and the capability of the MASW method are discussed and compared with the results of seismic reflection/refraction method and borehole data. Most of the borehole data is available through the GSC website (Natural Resources of Canada online maps [3]).

A particular issue in the Ottawa area is that the majority of the city, mainly the eastern and southern areas, is situated on very loose late glacial and postglacial sediments that overlay very high shear wave velocity bedrock (mostly limestone from Ordovician period). The shear wave velocity contrast between the very loose soil (usually with a shear wave velocity of less than $200 \mathrm{~m} / \mathrm{s}$ ) and the very firm rock (with a shear 
TABLE 1: Main field parameters for different MASW tests.

\begin{tabular}{|c|c|c|c|c|c|c|c|c|}
\hline MASW method & $\begin{array}{l}\text { Spread } \\
\text { type }\end{array}$ & $\begin{array}{c}\text { Spread } \\
\text { length }(\mathrm{m})\end{array}$ & $\begin{array}{c}\text { Receiver } \\
\text { spacing } \\
(\mathrm{m})\end{array}$ & $\begin{array}{c}\text { Source- } \\
\text { Receiver } \\
\text { offset }(\mathrm{m})\end{array}$ & $\begin{array}{c}\text { Record length } \\
\text { (S) }\end{array}$ & $\begin{array}{c}\text { Sampling } \\
\text { interval } \\
(\mathrm{m}-\mathrm{S})\end{array}$ & $\begin{array}{c}\text { Stack } \\
\text { number }\end{array}$ & Coupling \\
\hline Active & Linear & $11.5-46$ & $0.5-2$ & $10-35$ & $1-2$ & $1-2$ & 5 & Spike/Plate \\
\hline Passive roadside & Linear & $34.5-80.5$ & $1.5-3$ & NA & 30 & 4 & 5 & Spike/Plate \\
\hline Passive remote & Triangular & 40 & 1.5 & NA & 60 & 4 & 5 & Spike \\
\hline
\end{tabular}

TABLE 2: Frequency-phase velocity $\left(V_{c}\right.$ in $\left.\mathrm{m} / \mathrm{sec}\right)$ of dispersion curves for soil profiles obtained in Figure 6 . $\left(V_{c}\right)_{\text {extracted }}$ is the phase velocity of the extracted dispersion curve. $\left(V_{c}\right)_{1.4},\left(V_{c}\right)_{1.6},\left(V_{c}\right)_{1.8},\left(V_{c}\right)_{2.5},\left(V_{c}\right)_{2.8}$, and $\left(V_{c}\right)_{3}$ denote the phase velocity value for the initial profiles having the bedrock velocities of $1.4,1.6,1.8,2.5,2.8$, and $3 \mathrm{~km} / \mathrm{sec}$, respectively.

\begin{tabular}{lccccccc}
\hline Frequency $(\mathrm{Hz})$ & $\left(V_{c}\right)_{\text {extracted }}$ & $\left(V_{c}\right)_{1.4}$ & $\left(V_{c}\right)_{1.6}$ & $\left(V_{c}\right)_{1.8}$ & $\left(V_{c}\right)_{2.5}$ & $\left(V_{c}\right)_{2.8}$ & $\left(V_{c}\right)_{3}$ \\
\hline 2.2 & 1600 & 1830 & 1450 & 2070 & 1920 & 1640 & 2150 \\
2.4 & 400 & 320 & 430 & 400 & 370 & 520 & 350 \\
2.6 & 150 & 200 & 160 & 200 & 180 & 160 & 190 \\
3 & 100 & 95 & 90 & 110 & 100 & 110 & 100 \\
3.4 & 100 & 90 & 100 & 110 & 110 & 100 & 90 \\
4 & 100 & 100 & 100 & 100 & 90 & 95 & 100 \\
4.3 & 100 & 100 & 105 & 90 & 100 & 95 & 110 \\
4.6 & 100 & 105 & 90 & 100 & 110 & 95 & 95 \\
5.5 & 100 & 90 & 100 & 110 & 100 & 95 & 95 \\
5.9 & 100 & 95 & 90 & 100 & 100 & 90 & 90 \\
6.5 & 100 & 100 & 100 & 90 & 110 & 100 & 100 \\
7 & 100 & 100 & 90 & 100 & 90 & 90 & 100 \\
7.4 & 100 & 100 & 105 & 110 & 100 & 110 & 110 \\
8 & 100 & 100 & 95 & 100 & 90 & 90 & 100 \\
8.3 & 100 & 90 & 100 & 100 & 100 & 100 & 90 \\
9 & 100 & 94 & 90 & 90 & 100 & 90 & 85 \\
9.8 & 100 & 100 & 100 & 95 & 90 & 100 & 80 \\
\hline
\end{tabular}

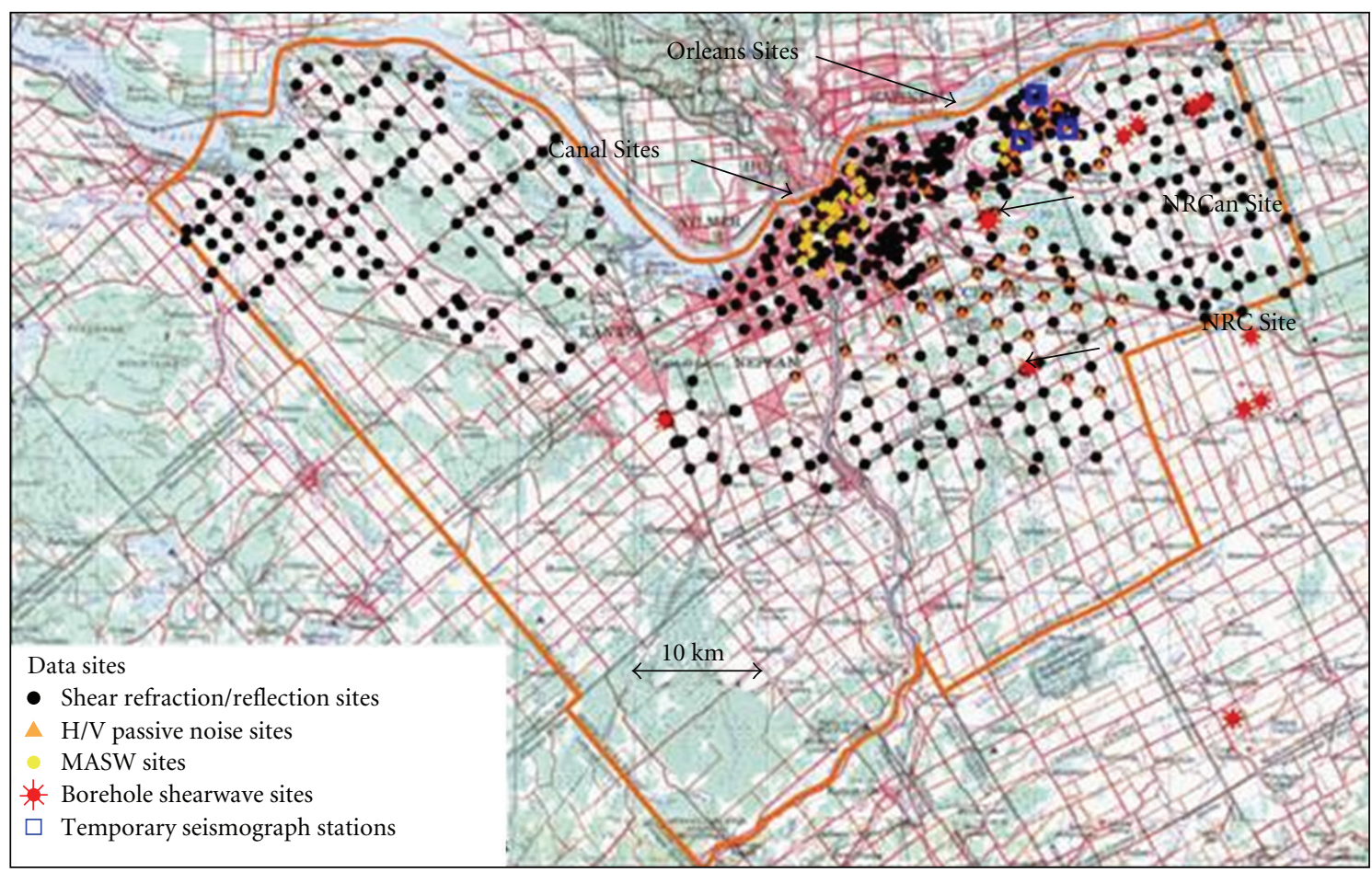

Figure 1: City of Ottawa and the research sites. 


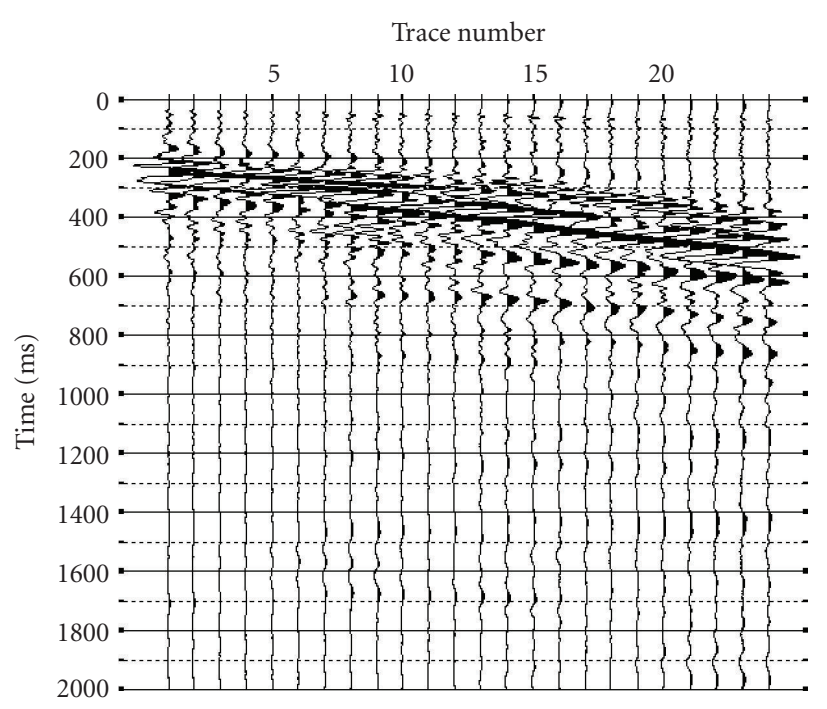

FIgure 2: Sample shot gather from the MASW method for the Brantwood site located around the Rideau Canal of Ottawa.

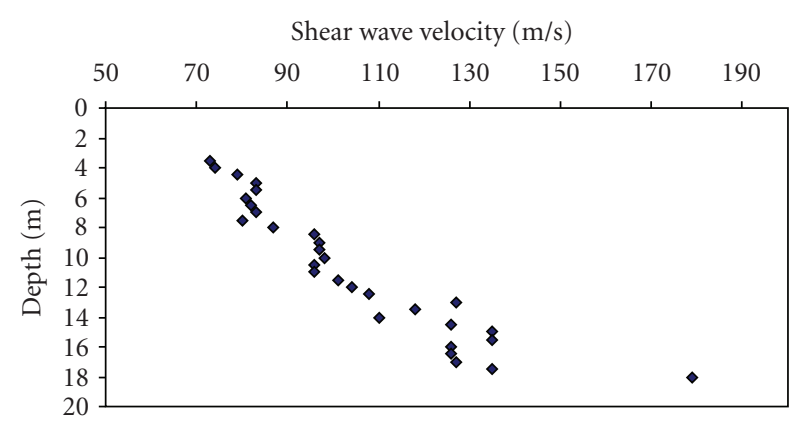

FIGURE 3: Depth-shear wave velocity profile from borehole data for NRC site.

wave velocity of usually more than $2,300 \mathrm{~m} / \mathrm{s}$ ) is very high; from a scientific and practical point of view, it is interesting to investigate the capability of MASW method in the study area as a guide for future microzonation measurements. Delineation of high contrast shear wave velocity boundaries has not been specifically addressed in previous MASW case studies, and this research is focused on the MASW capability and efficiency under such conditions in the Ottawa area.

For two special sites with available and accurate borehole data (GSC Anderson Road Site or NRCan site, and NRC Geotechnical site shown in Figure 1), the results of the active MASW method in soft sediments were evaluated against this borehole data to confirm the reliability of the method, in the presence of high shear wave velocity bedrock at depth. The passive remote and active MASW methods were also tested in the soccer field of Carleton University to distinguish the high shear wave velocity bedrock, and their results were evaluated against nearby borehole data (Natural Resources of Canada online maps [3]) and seismic refraction/refection methods. Some sites around the Rideau Canal, which is in the middle part of the city, were also examined to locate shallow bedrock and trace the very sharp contrast in shear

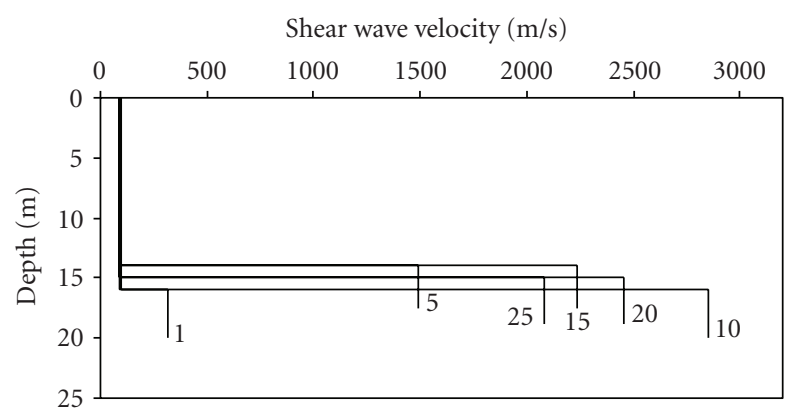

FIGURE 4: Layer models of depth-shear wave velocity for NRC site. Shear wave velocity profiles for different contrast ratios of the initial model, shown at the end of each profile. In the initial models, bedrock depth and average soil velocity values are fixed.

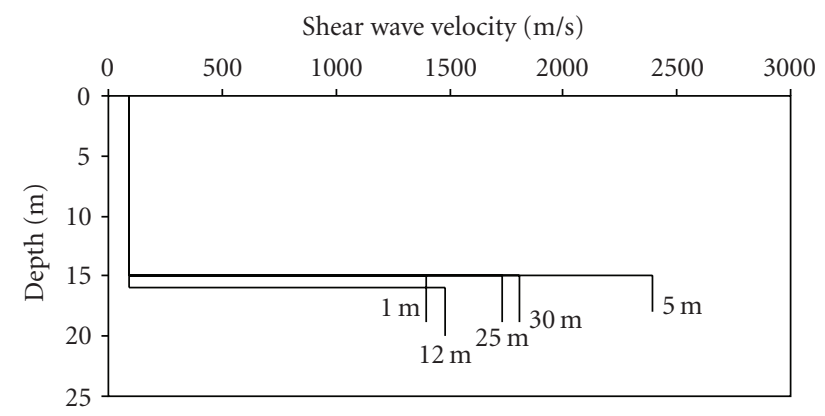

FIGURE 5: Layer models of depth-shear wave velocity for NRC site. Shear wave velocity profiles for different bedrock depth of the initial model, shown at the end of each profile. Contrast ratio and average soil velocity values are fixed.

wave velocities from less than $200 \mathrm{~m} / \mathrm{s}$ in soft sediments to $2,300 \mathrm{~m} / \mathrm{s}$ in bedrock at shallow depth. Also, four sites in the Orleans area (eastern part of the city) were selected to examine the functionality of the MASW methods for these semi-deep bedrock sites. Previous studies (Motazedian and Hunter [4]; GSC preliminary map for the Orleans area [5]), which provide robust references for comparison with the velocity-depth results in the Orleans area, are available.

\section{MASW Method}

Multistation gathers (i.e. several receivers along a surveying line that record a shot) are used commonly in shallow geophysics. The MASW method, as a nondestructive test, is gaining popularity among geotechnical engineers and geophysicists, due to its wide range of applications and advantages. For instance, MASW has been employed to locate buried structures (Tallavó et al. [6]) and to detect and image underground cavities (Nasseri-Moghaddama et al. [7]; $\mathrm{Xu}$ and Butt [8]). In addition to geophysical/geotechnical applications, MASW has been employed in infrastructure engineering. For example, Cascante et al. [9] used MASW to assess the conditions of the masonry sidewalls of the Navigli channels in downtown Milan, Italy and to identify the weaker sections, by considering stress wave parameters. As a significant geotechnical engineering application in many 
earthquake prone areas, MASW provides a tool for soil classification maps (e.g., [10]) based on the average shear wave velocity values for the top $30 \mathrm{~m}$ of the soil. In summary, popular applications of MASW include imaging of near surface heterogeneity, evaluation of rigidity of near surface materials, and estimation of shear wave velocity.

The main concept of MASW is based on the spectral analysis of surface waves (SASWs) method, which was developed by Heisey et al. [11], Nazarian et al. [12], and Nazarian [13]. The SASW method uses a single pair of receivers with an impulsive source and should be repeated several times for different soil/geophone configurations. Although the effectiveness of the method has been verified by many researchers, an expert user is needed to interpret the data (Crice [14]).

The important characteristic of the SASW and MASW methods is related to the inherent dispersive behavior of Rayleigh waves, since each frequency of the surface waves has a different propagation or phase velocity. Hence, it is viable to obtain the velocity at different depths when considering the fact that the each frequency represents a specific penetration depth. One of the advantages of MASW and SASW is their capability in using Rayleigh waves to provide an estimate of shear wave velocity at different depths. This is important because surface (Rayleigh) waves carry more than two thirds of the total radiated seismic energy (Richart et al. [15]) from a surface seismic source; Rayleigh wave's strong energy leads to a high signal-to-noise ratio in an urban area, where the background noise is very high due to local traffic.

There are two types of MASW methods: active and passive. In the active MASW method, multiple receivers (geophones) are positioned along a survey line (spread). Receivers, which are mounted on land streamer plates with even spacing, are located along the survey line and connected to a seismograph. A seismic source (a sledgehammer or a vibratory machine that operates vertically) generates seismic waves, which are gathered by a seismograph and recorded on a computer. In this study, we used a 24-channel Geometrics Geode seismograph, with vertical $4.5 \mathrm{~Hz}$ geophones. There were two different types of coupling between the geophones and the ground: loose coupling (geophones are mounted on land streamer plates that simply lie on the ground) and tight coupling (geophones are planted in the ground using spikes). The latter provides an improved coupling while the former covers a long profile in a shorter time, because the land streamer plates are connected with a strong rope allowing a faster shift of the entire spread over a long profile to cover a two-dimensional (2D) velocity profile. This $2 \mathrm{D}$ imaging method is increasingly becoming the trend in the utilization of MASW (Lin et al. [16]; Xia et al. [17]) since such a land streamer approach increases the MASW productivity in geotechnical engineering practices.

The passive MASW method uses directional background noise generated by traffic as a seismic source. In this research, we used the passive roadside MASW method (Park and Miller [18]), in which the geophone line is oriented parallel to a road, recording surface waves generated by traffic. The offline distance between the road and the survey line is kept fairly constant throughout the entire survey. Furthermore,

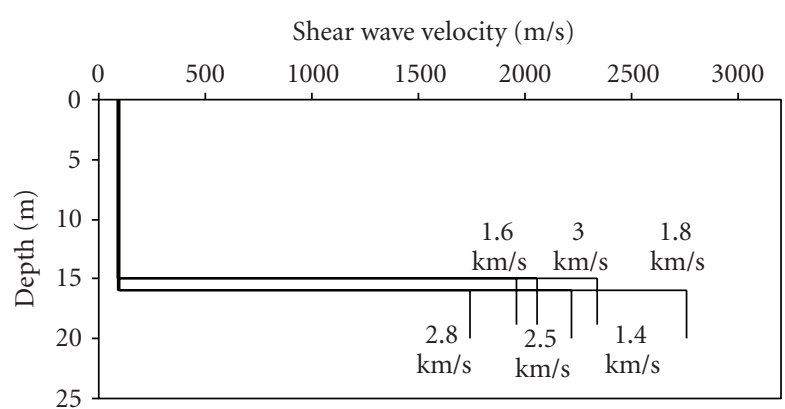

FIGURE 6: Layer models of depth-shear wave velocity for NRC site. Shear wave velocity profiles for different bedrock velocities (in $\mathrm{km} / \mathrm{sec}$ ) of the initial model, shown at the end of each profile. Contrast ratio and bedrock depth velocity are fixed.

surface waves generated by natural or cultural sources are usually of lower frequencies, providing the possibility of deeper penetration. Recently, there has been strong motivation in using these sources in the passive MASW method, which is usually called the remote passive MASW. In this method, a linear lineup of geophones is not capable of capturing the complicated characteristics of the passive sources; and a 2D symmetrical array of geophones, including circular, cross, square, triangular, or random configurations, is suggested, as long as the symmetrical shape of the array is satisfied during these surveys. Increasing the dimensions of the array provides information from a deeper area, because the array dimensions are directly related to the longest wavelength, which determines the maximum depth of investigation (Park et al. [19]).

Although, the passive MASW method provides shear wave velocity to greater depths compared to the active MASW method (Louie [20]; Okada [21]), it is usually applied when the active method fails to provide the shear wave velocity information for the required depth in urban areas, mainly because passive MASW method requires greater open space, which is not feasible in the most urban areas.

\section{Dispersion Curves and Inversion Techniques}

The conventional MASW method has three main steps: (i) acquisition of Rayleigh wave data, (ii) construction of the dispersion curves for the Rayleigh wave (the fundamental mode of a Rayleigh wave in this research), and (iii) the inversion process of the Rayleigh wave to obtain shear wave velocity. The first step, data acquisition, is based on the type of the array used in the different passive and active MASW methods. A sample shot gather of acquired data is shown in Figure 2. In the second step, the dispersion curve for the Rayleigh wave, which is the phase velocity versus frequency, is constructed, and the fundamental mode of the dispersion curve is determined.

A number of methods have been introduced for extracting of the dispersion curves (Heukelom and Foster [22]; Jones [23]; McMechan and Yedlin [24]; Park et al. [25]; Zywicki and Rix [26]; Ashiya et al. [27]; Zhang et al. [28]). In 


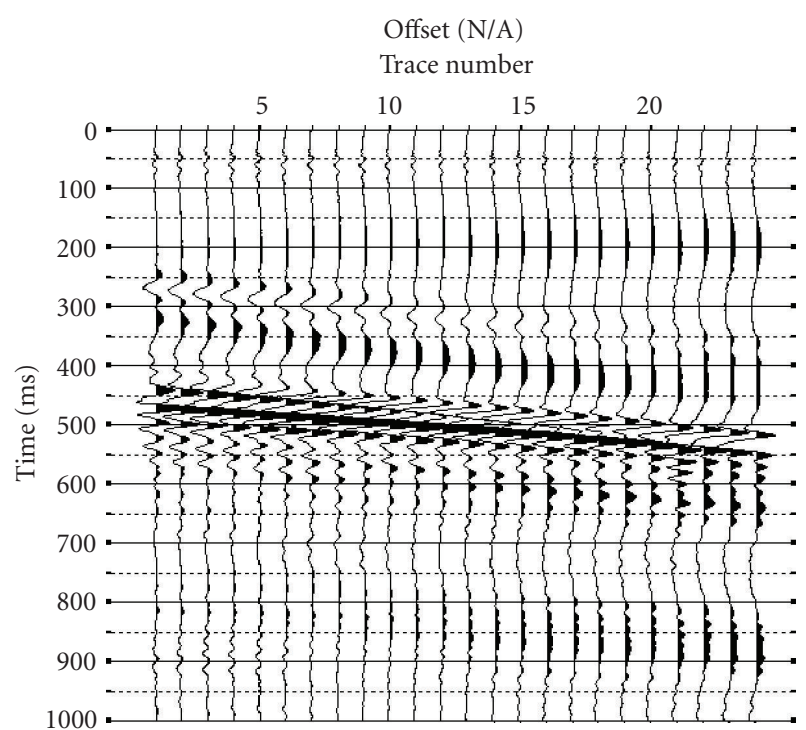

FIGURE 7: Sample shot gather from the MASW method for the NRC site.

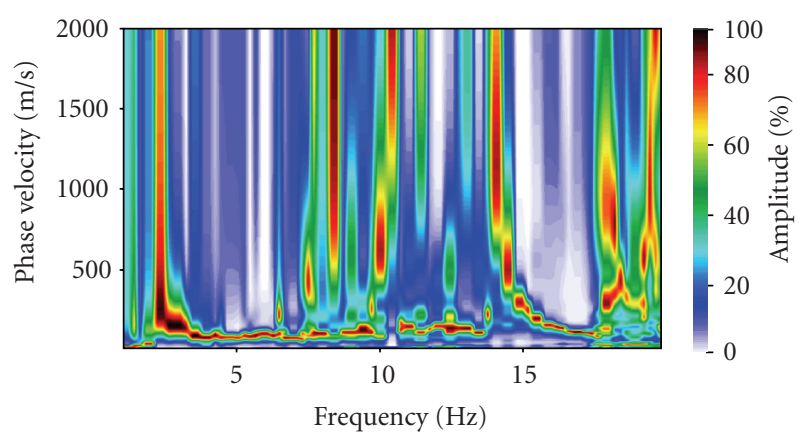

FIGURE 8: Sample overtone image of the dispersion curve from the combined MASW method for the NRC site located in the southern part of the city of Ottawa.

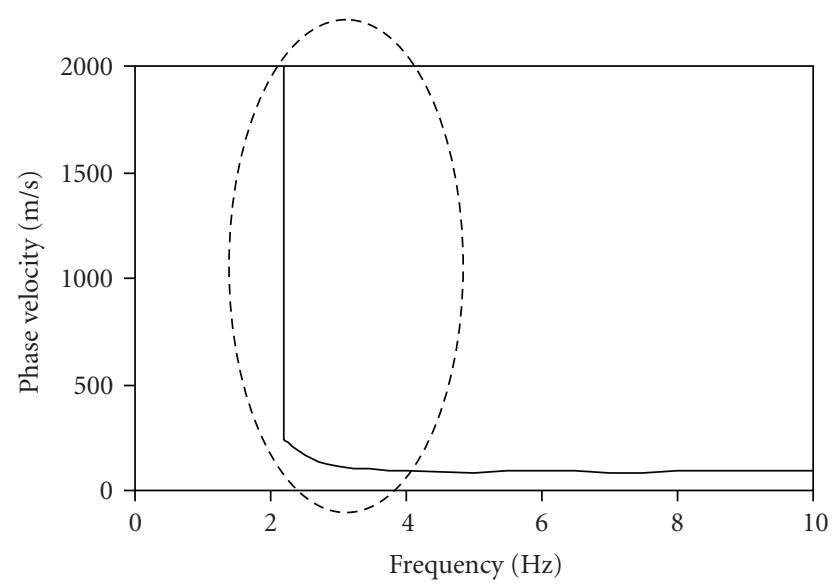

FIGURE 9: Dispersion curve for the fundamental mode of the passive roadside MASW method for NRC site. The part of curve that is located inside the dashed ellipse $(\leq 5 \mathrm{~Hz})$ comes from the passive roadside test.

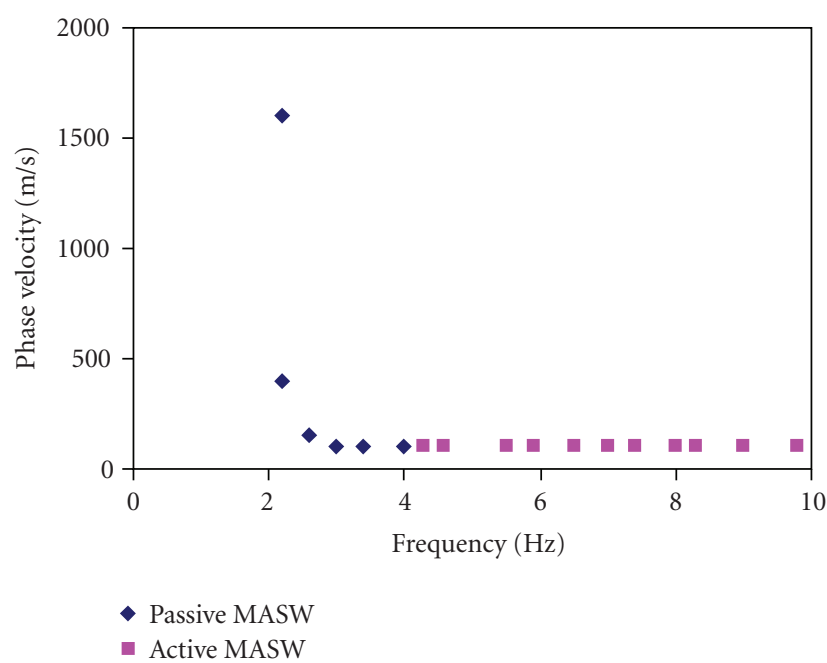

FIGURE 10: Picked points on the dispersion curve of the fundamental mode of Rayleigh wave for NRC site.

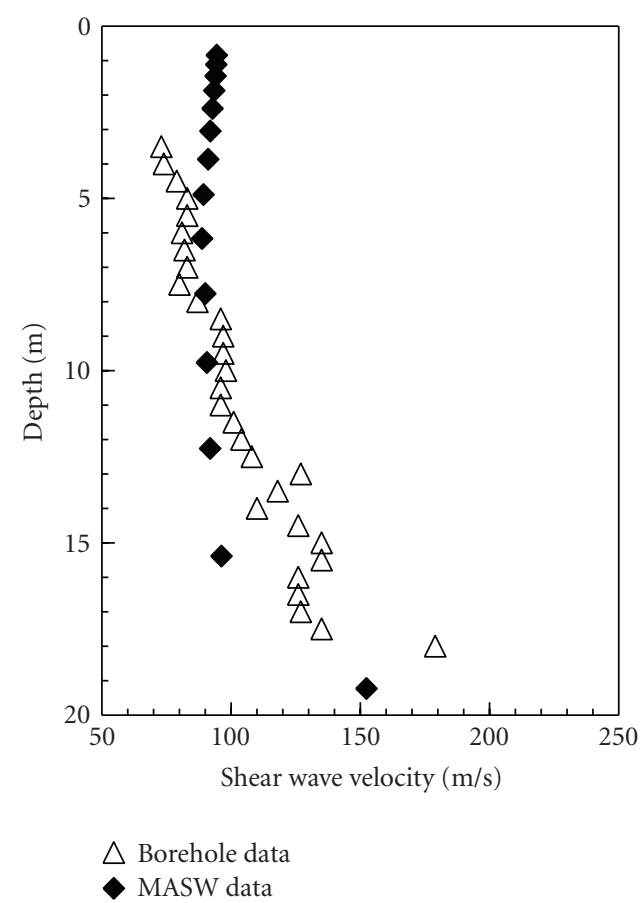

FIGURE 11: Comparison between shear wave velocity models based on MASW method using multilayer soil model and borehole data (downhole shear wave velocity measurement in a borehole located $30 \mathrm{~m}$ away from MASW site) for NRCan site.

this study, we applied the wavefield transformation technique (McMechan and Yedlin [24]; Park et al. [25]), which aims at getting the dispersion spectrum from multi-channel surface wave data. Zhang et al. [28] showed that this technique gives a better representation of the dispersion behavior of the Rayleigh waves than that of the previous techniques. Details of this technique can be found in Appendix A.

During the recent years, older methods based on steadystate Rayleigh waves (Jones [23]; Heukelom and Foster [22]) 


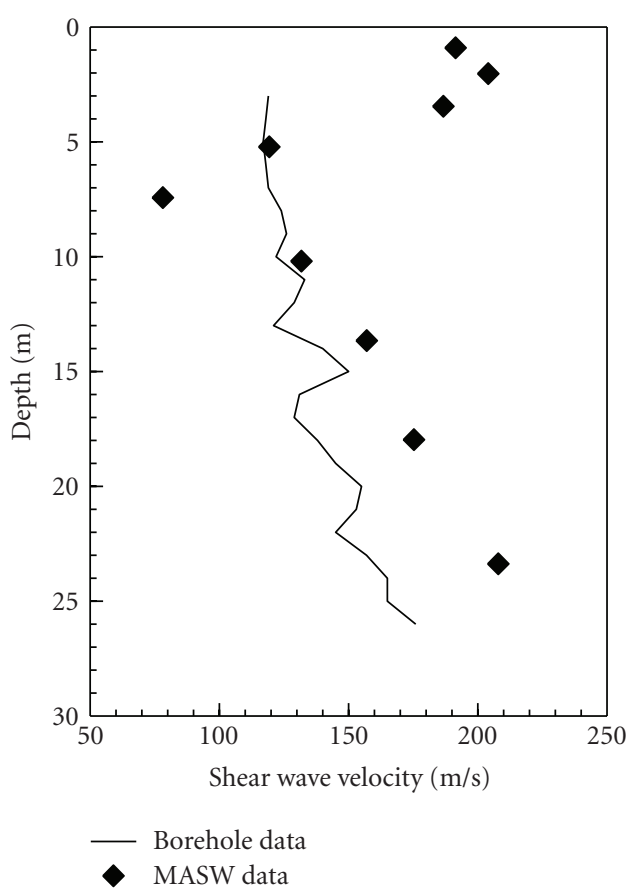

FIgURE 12: Comparison between shear wave velocity values of MASW results (initial multilayer model) and borehole data for the GSC Anderson Road site (NRCan site).

were shown to be inappropriate for layered models. Another method, the frequency-wave number (F-K) method (Zywicki and Rix [26]; Ashiya et al. [27]) is based on the imaging of the stacked energy in F-K space. Zhang et al. [28] showed that the extracted velocities from the F-K method are apparent velocities, rather than fundamental mode ones, and can cause erroneous outcomes in the inversion process.

In the third step of MASW processing, the shear wave velocity is inverted from the dispersion curve of the Rayleigh wave. It has been shown that the inverted one-dimensional (1-D) shear wave velocity model is an average of the earth material beneath the geophone spread, and it is reasonable to locate an inverted 1-D shear wave velocity model in the middle of the geophone spread (e.g. Luo et al. [29]). There are two different inversion techniques used in the MASW method: (i) Monte Carlo or random search inversion, and (ii) generalized inversion. In both inversion techniques, forward modeling is applied on an initial model, which is given by the user. Then, one of the inversion techniques is applied to provide the shear wave velocity values at different depths from the dispersion curve.

The generalized or nonlinear inversion techniques rely on analytical solutions, while the random search inversion approach considers a suitable initial velocity profile as the initial guess of the inversion and uses a random search algorithm to revise the initial profile. The advantages of random search algorithms have been studied by a few researchers. For instance, Ryden and Park [30] used the fast simulated annealing (FSA) global search algorithm (Szu and Hartley [31]), which seeks the best match between the

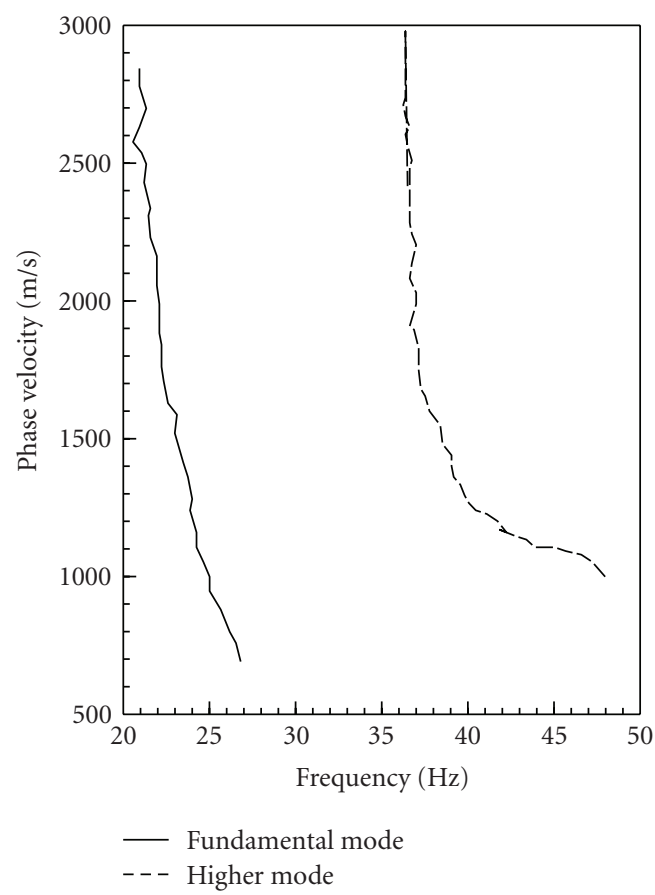

FIgure 13: Dispersion curves of the fundamental mode and a higher mode (first mode) of the Rayleigh wave obtained from the combination of the active and remote passive MASW methods for the soccer field of Carleton University.

measured and modeled phase velocity spectrum. According to Ryden and Park [30], the random search inversion method is less likely to get trapped in local minima, which may occur with a generalized inversion method. In the current study, we show that random search inversion has some advantages over generalized inversion in distinguishing the high shear wave velocity contrast and detecting the depth of bedrock for our target sites. The description of these advantages is presented in the "Discussion" part of this paper.

Zhang and Chan [32] studied the effects of the sample interval and the truncated frequency range on the accuracy of the inversion model. Their study shows that the accuracy of inversion models depends on: (i) small sample intervals over a wide frequency range, and (ii) proper identification of the fundamental mode. According to this study, the sensitivity of the inversion model is highly dependent on the acquired dispersion data of the low frequency range, because low frequencies related to long wavelengths provide the information of deeper layers. These findings justify the application of combined active and passive MASW tests, as performed in the present research, which provide the information associated with the low frequency range of the dispersion curves.

\section{MASW Software}

In this research, we used Surfseis software (Park [33]), which provides two different inversion techniques: (i) random search inversion, and (ii) analytical nonlinear inversion using 
TABLE 3: Comparison between estimated MASW results and borehole data for shallow bedrock (canal sites).

\begin{tabular}{lcccc}
\hline Site Name & $\begin{array}{c}\text { Bedrock Velocity (from } \\
\text { MASW) }\end{array}$ & $\begin{array}{c}\text { Bedrock Layer Depth } \\
\text { (from MASW) }\end{array}$ & $\begin{array}{c}\text { Bedrock Depth (from the } \\
\text { closest GSC borehole } \\
\text { results) }\end{array}$ & Bedrock Depth Errors \\
\hline Brantwood park & $2,943(\mathrm{~m} / \mathrm{s})$ & $9-11.25 \mathrm{~m}$ & 7.7 & $14.5 \%$ \\
Bordeleau park & $2,662(\mathrm{~m} / \mathrm{s})$ & $4-5 \mathrm{~m}$ & 4.7 & $15 \%$ \\
McDonald park & $2,326(\mathrm{~m} / \mathrm{s})$ & $10-12 \mathrm{~m}$ & 9.5 & $5 \%$ \\
Robinson Park & $2,584(\mathrm{~m} / \mathrm{s})$ & $7-8.75 \mathrm{~m}$ & 5.9 & $15.8 \%$ \\
New Edinburgh Park & $2,245(\mathrm{~m} / \mathrm{s})$ & $5-6.25 \mathrm{~m}$ & 4.1 & $18 \%$ \\
Browns inlet Park & $2,433(\mathrm{~m} / \mathrm{s})$ & $1-2 \mathrm{~m}$ & 0.9 & $10 \%$ \\
Windsor Park & $2,772(\mathrm{~m} / \mathrm{s})$ & $4-5 \mathrm{~m}$ & 5 & $20 \%$ \\
Brewer Park & $1,953(\mathrm{~m} / \mathrm{s})$ & $5.2-6.5 \mathrm{~m}$ & 5.4 & $4 \%$ \\
Rideau River Park & $1,890(\mathrm{~m} / \mathrm{s})$ & $11-13.75 \mathrm{~m}$ & 9.1 & $17.3 \%$ \\
\hline
\end{tabular}

the weighted least squares algorithm. In the random search approach, an initial shear wave velocity profile is used, and the theoretical dispersion curves are generated using the forward modeling scheme of Schwab and Knopoff [34]. Then, using a random procedure, the searching process is started to match the theoretical and extracted dispersion curves; and, in an iterative procedure, the initial model is updated, until the desired accuracy is satisfied. In the second method of inversion, a constrained least squares algorithm is applied to find the shear wave velocity profile (See Appendix B). This is an automated, but computationally intensive method. This technique becomes faster and more efficient when the algorithm introduced by Xia et al. [35] is used. They proposed an objective function as the constrained (weighted) least square method that makes the convergence procedure stable in iterations of the inversion. They applied iterative solutions with their weighted equation using the Levenberg-Marquardt (Marquardt [36]) method and the singular value decomposition (SVD) technique (Golub and Reinsch [37]) and showed the efficiency of the calculation and the stability of the inversion procedure. Appendix B provides more details on the generalized inversion technique.

\section{MASW Case Studies}

Successful MASW case studies have been reported in the literature. For brevity, just a few of them are mentioned here:

(1) To validate the MASW technique, MASW shear wave velocity profiles were statistically compared to shear wave velocity profiles measured in eight boreholes in unconsolidated sediments of the Fraser River delta, near Vancouver, British Columbia, Canada. The agreement between the methods was good, and an overall difference of $15 \%$ or less was observed between the shear wave velocities derived from the two methods (Xia et al. [38]). The database of the mentioned borehole-derived shear wave velocities can be found in Hunter et al. [39].

(2) MASW tests were carried out at eight Norwegian research sites (Long and Donohue [40]; and, it was shown that the MASW shear wave velocity profiles

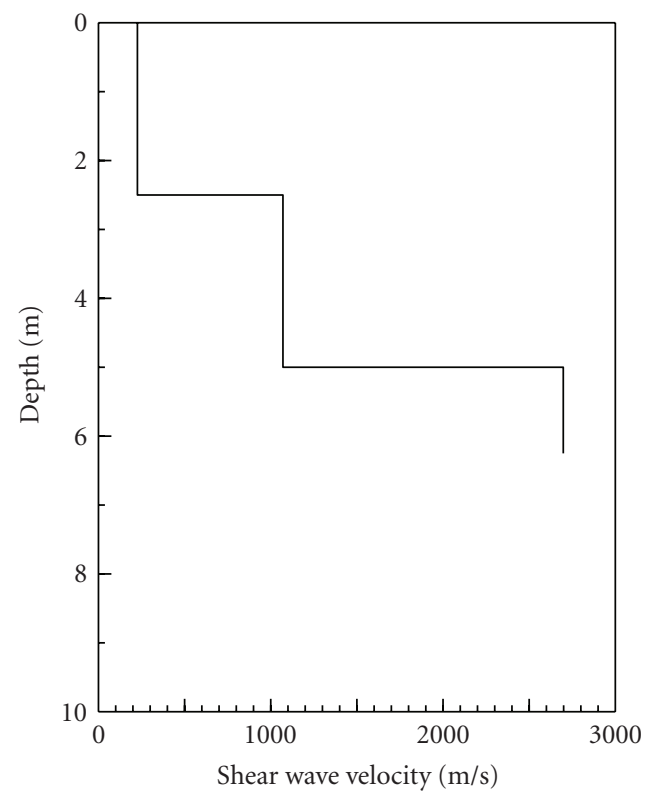

FIGURE 14: $V_{s}$ profile for the soccer field of Carleton University, based on random search inversion. The great velocity jump is obvious at the depth of $5 \mathrm{~m}$.

are similar to those of other techniques, such as the cross-hole seismic test and the seismic cone penetrometer test (SCPT).

(3) Richwalski et al. [41] used MASW, in parallel with four other popular geophysical techniques, for the estimation of the local site effects in Germany and achieved consistent results from the dispersion curves of the Rayleigh wave.

(4) Thitimakorn et al. [42] carried out 2D interpretations of MASW to estimate the shear wave velocity profile and depth of bedrock in downtown St. Louis, Missouri, USA. They compared their interpreted results with borehole, cone penetrometer and seismic cone penetrometer data and found good correlation between these geotechnical data and the MASW results. 


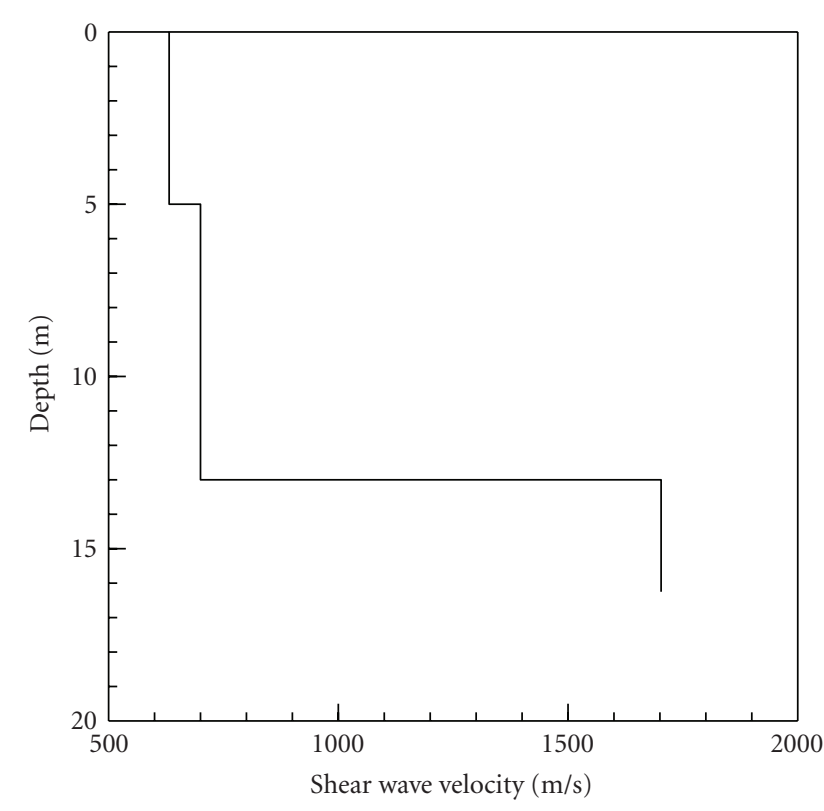

Figure 15: $V_{s}$ profile for Soccer Field of Carleton University based on the extracted dispersion curve and analytical generalized inversion.

(5) Hoffman et al. [43] compared shear wave velocity data from MASW tests with SCPT, cross-hole and ultrasonic pulse velocity methods and recommended the MASW method as the quickest and the most economical technique.

Since high contrast shear wave velocity boundaries have not been addressed in previous studies, in the current MASW research program, we covered different sites and locations across the city of Ottawa to study the capability and efficiency of the MASW method and inversion techniques, in order to distinguish this contrast. We investigated 16 sites in the Ottawa area, shown in Figure 1, to evaluate the capability of both the passive and active MASW methods for near surface seismic soil classification purposes, based on the shear wave velocity-depth function. These locations include: one the GSC Anderson Road Site (NRCan site), four sites in the eastern part of the city (Orleans sites), ten sites around the Rideau Canal (canal sites plus the site located in the soccer field of Carleton University), and one site that is located in the south (NRC Geotechnical Site). These sites were selected for the following reasons:

(1) Two sites (NRC, Geotechnical Site in the south and GSC Anderson Road Site (NRCan site) in the east) were chosen due to the availability of accurate data from nearby boreholes and seismic refraction/reflection measurements. The main objective was calibration of the passive and active MASW methods with other reliable geophysical/geotechnical methods.

(2) A few sites (canal sites) were chosen due to the presence of shallow bedrock. The objective was evaluation of the capacity of this method in recognizing the shallow bedrock.

(3) A few sites (in the Orleans area) were chosen due to the presence of deep bedrock (the majority of that part of the city is mostly covered with thick soft clay). The main objective was evaluation of the ability and reliability of combined passive and active MASW methods to detect the deep and high velocity bedrock.

(4) One site (the soccer field of Carleton University) was chosen for 2D tests and passive remote MASW, due to the availability of a large field.

The main MASW parameters for all sites are given in Table 1. As shown in this table, different values were selected for the active, passive roadside and passive remote methods, depending on the nature of each method. The rationales behind their selection are:

(1) The array dimensions and spacing between the geophones should be larger for the passive MASW method, because this method aims to investigate deeper zones.

(2) In the active MASW method, the offset distance, which is the distance between the source and the first receiver, should lie within a specific range. Short distances (usually less than $10 \mathrm{~m}$ ) lead to a nonplanar propagation of Rayleigh waves, resulting in reduced energy or coherency in the recorded signals. On the other hand, at large distances (usually greater than $100 \mathrm{~m}$ ), the signal-to-noise ratio is decreased, because the body waves and the higher modes dominate the fundamental mode of the Raleigh wave.

(3) The natural frequency of the 24 geophones is as low as $4.5 \mathrm{~Hz}$, since higher frequency geophones are good for only shallower depths. For deeper investigations, lower natural frequency is more appropriate.

(4) The spacing between the geophones has a direct relation with the required depth resolution. Large spaces between the geophones decrease the resolution of the constructed dispersion curves. This parameter is more important in the active MASW method. As shown in Table 1, the maximum receiver spacing is limited to $2 \mathrm{~m}$ for the active MASW method.

A $12 \mathrm{lb}$ sledgehammer was chosen as the seismic source for the active MASW method. In the roadside passive MASW method, moving heavy cars or trucks or their combinations were used for greater penetration depth of the waves.

\section{Discussions}

6.1. Sensitivity of the Results to the Input Parameters of the Initial Model in Random Search Inversion. MASW method has been used for the detection of underlying high velocity bedrock. For instance, Casto et al. [44] showed that the information of dispersion data is useful for the resolving of depth and the velocity of high-velocity bedrock. As another 
example, the recently published paper by Casto et al. [45] exhibits the capability of MASW to recognize the high velocity bedrock layer. In the current research, for one of the sites with available borehole information and the presence of bedrock in the top $18 \mathrm{~m}$ (NRC site), the sensitivity of the inverted depth-velocity profile was evaluated for the variation of different input parameters in the initial model of random search inversion. The comparison benchmark (target profile) was the borehole site, which is $30 \mathrm{~m}$ away from the NRC site. According to the borehole data (Figure 3), which shows downhole shear wave velocity measurements, bedrock was detected at the depth of $18 \mathrm{~m}$ (ending point for soil velocity values) and is overlain by a loose soil with the average shear wave velocity around $100 \mathrm{~m} / \mathrm{s}$. Also the bedrock velocity was measured as $2,300 \mathrm{~m} / \mathrm{s}$ using the reflection/refraction method.

To carry out the sensitivity analysis of the initial soil model we applied the random search inversion technique and we chose 2-layer model (one layer for the entire soft clay and one for the underlying bedrock). Shear wave velocity contrast, as the first input parameter of the initial model, was given different values, while the bedrock depth and average shear wave velocity of soil were kept constant in the initial model. In other words, while keeping the deposit depth of $18 \mathrm{~m}$ and the corresponding average shear wave velocity of $100 \mathrm{~m} / \mathrm{sec}$ constant, the shear wave velocity of the bedrock was increased by the factors of 1, 5, 10, 15, 20 and 25 times of soft soil velocity. Figure 4 illustrates the final inverted 2layer velocity-depth profiles for the different values of shear wave velocity contrast. As shown in Figure 4, using the shear wave velocity contrast ratios equal or greater than 10 for the initial model, the utilized random search inversion delivers the bedrock velocity values within a relatively reasonable range $(2100 \mathrm{~m} / \mathrm{sec}$ to $2800 \mathrm{~m} / \mathrm{sec})$.

As the second input parameter, the bedrock depth was given different values, while all other parameters (soil and bedrock velocities) were kept the same. As shown in Figure 5, the final bedrock depth is close to the borehole data, although the bedrock shear wave velocity can sometimes be underestimated. Finally, different values were also given to the bedrock shear wave velocity, the third input parameter, while all other input parameters (contrast ratio and bedrock depth) were kept unchanged, as shown in Figure 6. A sample of the dispersion curves (as misfit functions) for different initial profiles of Figure 6 are given in Table 2.

The borehole data indicates that the bedrock is located at a depth of $18 \mathrm{~m}$, and the average shear wave velocity of the soil is around $100 \mathrm{~m} / \mathrm{s}$. Figures 4 to 6 indicate that the input parameters in the initial model can make a difference, depending on the expected accuracy from the MASW. We may conclude that, in the majority of cases, reasonable results were obtained for bedrock depth (from $14 \mathrm{~m}$ to $20 \mathrm{~m}$ ) and average shear wave velocity for loose soil (from $90 \mathrm{~m} / \mathrm{s}$ to $96 \mathrm{~m} / \mathrm{s}$ ), but some discrepancies existed in the estimation of the bedrock velocity. These disparities can be related to the effect of resonance occurring at the frequency of $2.2 \mathrm{~Hz}$, which results in high phase velocity values. Another reason for the bedrock velocity discrepancies is the distance between the borehole location and MASW sites (30 m apart from each other), which may cause different velocity values. Thus, the available geological and geotechnical information as input parameters in the initial model can improve the results of MASW method.

6.2. Advantages of Random Search Inversion. As mentioned above, a high shear wave velocity contrast exists between very loose soil and very hard bedrock for the majority of the sites in the city of Ottawa. In this research, due to this high contrast interface in the study area, an attempt was made to find the most efficient method of inversion to accurately differentiate the soil from the bedrock in the shear wave velocity-depth function. Between the two aforementioned conventional inversion methods, random search inversion was found to be the most efficient in locating the high contrast interface in the study area. The success of this method is due to two probable reasons:

(1) There is only a slight possibility that this inversion method may get trapped in local minima (Ryden and Park [30]).

(2) This technique benefits from extra flexibility in the updating of both the variables of depth and velocity. This feature does not exist in the generalized inversion method.

In random search inversion, the forward modeling is performed based on an initial velocity-depth model constructed within a reasonable range of velocities. The initial velocity-depth model prevents the divergence of the velocity values from the real profile. This simply means that, although this method provides good results, there should be some regional information on the geology of the area, which is useful in all geophysical methods. Random search inversion can then be set for the different velocity increments around the initial model. Using this random search ability, theoretical dispersion curves of the velocity-depth functions are compared with the extracted dispersion curves; and, these profiles get updated iteratively until the errors reach the desirable minimum values.

\subsection{Bedrock Depth and High Contrast Shear Wave Velocity} Detection. Active and passive MASW methods were applied to 16 sites in the city of Ottawa; and, using the aforementioned modeling parameters given in Table 1 and utilizing Surfseis software (Park [33]), the dispersion curves were constructed and the shear wave velocity-depth function was obtained.

At one of the sites with available borehole information and presence of bedrock in the top $30 \mathrm{~m}$ (NRC site), the borehole site, which is $30 \mathrm{~m}$ away from the NRC site, was previously utilized for downhole shear wave velocity determination, one of the most accurate methods for shear wave velocity measurements Figure 7 demonstrates a sample shot gather from the MASW method for the NRC site. Moreover, Figure 8 illustrates the overtone image of the combined MASW method for this site. The method of combination is based on the overtone image extraction for each of the active and passive methods. Then these 
images are combined together, and therefore the missing low frequency range in active method is covered by the passive test. The procedure of combination is performed using the commercial software, Surfseis 2. In this procedure, the overtone image is established according to the energy percentage of the surface waves (in frequency-phase velocity space). For example, Figure 8 demonstrates the fundamental mode of Rayleigh wave by red color for the energy percentage more than $80 \%$ (see energy bar on top of the Figure).

For NRC site, Figures 9 and 10 show the experimental fundamental mode dispersion curve and the picked points on this curve respectively. As mentioned, the passive roadside MASW was combined with active MASW at this site to improve the results at lower frequencies. The phase velocity values between $2.2 \mathrm{~Hz}$ and $4 \mathrm{~Hz}$ (in Figures 9 and 10) are from passive MASW; and, the higher frequency $(>4 \mathrm{~Hz})$ values are from active MASW. Finally, the inverted shear wave velocities (for a multilayer model) from MASW are compared with borehole results in Figure 11 that shows good agreement between two methods.

The other site with available borehole data and refraction/reflection measurements does not have bedrock in the top $30 \mathrm{~m}$ (GSC Anderson Road Site or NRCan site) and is located in the eastern part of the city of Ottawa. Shear wave velocity results are available for each meter of the borehole. The obtained shear wave velocity values from MASW (using a multilayer model) are close to borehole data up to 25 meters, as shown in Figure 12. The nearsurface high velocity points are related to an over consolidated layer. The upper few meters of the Champlain Sea sediments is an over-consolidated layer, which can be associated with late/post-glacial paleo-freeze-thaw cycles when the seabed was exposed, or desiccation in areas of raised marine's sediments. The thin high velocity surface layer might also be associated with artificially consolidated surface materials in some areas such as parks, roadbeds, and so forth.

For other sites with shallow bedrock (located around the Rideau Canal in the central area of the city), the random search inversion method was used to invert the depth-velocity function from the corresponding dispersion curves. Table 3 provides the MASW results and borehole information for the canal sites that are located on shallow bedrock. As shown in Table 3, due to the small difference between bedrock depths from borehole data and the MASW method the efficiency of MASW was confirmed for detection of the shallow bedrock in that area. The bedrock shear wave velocities resulting from MASW lie in the acceptable range (from $2,200 \mathrm{~m} / \mathrm{s}$ to $3,000 \mathrm{~m} / \mathrm{s}$ ), although underestimations arose for some sites. The depth of bedrock is also reasonably estimated by the MASW method. The errors in depth estimations are $14.5 \%, 15 \%, 5 \%, 15.8 \%, 18 \%, 10 \%$, $20 \%, 4 \%$ and $17.3 \%$ for sites in Table 2 , from the top to bottom, respectively. The discrepancies may be related to the reference boreholes, because they are located at least $100 \mathrm{~m}$ away from the examined sites. Thus, based on Table 3, the random search inversion technique can provide a reasonable estimation of depth and shear wave velocity in areas where the bedrock is shallow $(<30 \mathrm{~m})$.
The site for the 2D tests (Carleton University soccer field site) provides a large area for passive remote MASW measurements. The passive remote MASW method was combined with the active MASW method to increase the frequency range of the dispersion curve and improve the reliability of the total frequency range. For this site, the random search inversion method was applied to investigate the applicability of MASW for the high contrast interface between the soil and the bedrock. The dispersion curve was extracted (Figure 13) and using an initial 3-layer model; the shear wave velocity profile was inverted. The estimated bedrock depth, as shown in Figure 14, is $5 \mathrm{~m}$, which is very close to the results of the other geophysical measurements, such as near surface refraction/reflection methods and available local geological maps. The nearby GSC borehole (Natural Resources of Canada online maps [3]) with a $5.4 \mathrm{~m}$ bedrock depth confirms the results of the random search inversion. Furthermore, with this method, the inverted shear wave velocity was determined 2,698 m/s for the bedrock (See Figure 13), which is quite close to shear wave velocity obtained from reflection/refraction methods $(2,500 \mathrm{~m} / \mathrm{s})$. On the other hand, Figure 15 demonstrates the same inverted shear wave velocity profile using the generalized inversion technique and similar initial profile applied for random search inversion. According to this Figure, the bedrock is detected at the depth of $13 \mathrm{~m}$. This depth is far from the depth reported from the nearby borehole (depth of $5.4 \mathrm{~m}$ ). This example exhibits the advantage of the random search inversion over the generalized inversion for distinguishing the bedrock depth in the area.

Finally, the sites with deep bedrock (i.e. the Orleans area in the eastern part of the city) are located on a thick $(>40 \mathrm{~m})$ and very loose layer of soil (Motazedian and Hunter [4]; GSC preliminary map [5]). The combined passive roadside and active MASW methods were applied to estimate the bedrock depth and shear wave velocity using the random search inversion method. As shown in Table 4, although the velocity values seem reasonable (generally, the shear wave velocity is larger than $2,500 \mathrm{~m} / \mathrm{s}$ ); however, the estimated depths are quite different from values obtained from the reflection/refraction method. This depth issue may be resolved if more sensitive geophones and stronger sources are taken into account (improved signal-to-noise ratio). It seems that it is critical to increase the dispersion information regarding the low frequency range (down to $1 \mathrm{~Hz}$ ) for these deep and loose soil profiles.

\section{Conclusions and Recommendations}

Sixteen sites in the city of Ottawa were chosen to investigate the efficiency of MASW for high contrast shear wave velocity profiles and to study the suitable inversion techniques applicable to the velocity models. Results of the sensitivity analysis for the initial model indicate that, except for the case of the low contrast ratio values in the initial model, the velocity-depth data obtained from the random search inversion are in good agreement with the borehole data. In high contrast shear wave velocity profiles, like the majority of 
TABLE 4: Comparison between estimated MASW results and those of the reflection/refraction methods [5] for deeper bedrock in the Orleans area.

\begin{tabular}{lccc}
\hline Site Name & $\begin{array}{c}\text { Bedrock Velocity } \\
\text { (From MASW) }\end{array}$ & $\begin{array}{c}\text { Bedrock Layer } \\
\text { Depth (from MASW) }\end{array}$ & $\begin{array}{c}\text { Bedrock Contour Depth } \\
\text { (from Reflection/Refraction) }\end{array}$ \\
\hline Barrington Park & $3,030(\mathrm{~m} / \mathrm{s})$ & $69-86 \mathrm{~m}$ & $60-70 \mathrm{~m}$ \\
Carriere Park & $2,435(\mathrm{~m} / \mathrm{s})$ & $43-53 \mathrm{~m}$ & $50 \mathrm{~m}$ \\
Louis Perrault Park & $2,697(\mathrm{~m} / \mathrm{s})$ & $74-92 \mathrm{~m}$ & $80-90 \mathrm{~m}$ \\
Heritage Park & $2,677(\mathrm{~m} / \mathrm{s})$ & $76-95 \mathrm{~m}$ & $80-90 \mathrm{~m}$ \\
\hline
\end{tabular}

sites located in Ottawa, we strongly recommend using random search inversion over analytical generalized inversion. Random search inversion is less likely to become trapped in local minima and benefits from the flexibility to search for the best match velocity profile. Because the sensitivity of inversion techniques is dependent on the low frequency part of the dispersion curves, we recommend applying the combination of active and passive MASW methods to obtain this low frequency data at sites where deep layers of soil are examined. In summary, apart from the deficiency of the utilized MASW for very deep bedrock detection, it is concluded that MASW is capable of estimation of shear wave velocity-depth profiles, although this method can benefit from geological and geotechnical information for the input parameters in the initial model. It should be mentioned that NHERP site classes are based on the shear wave velocity for the top $30 \mathrm{~m}$ of soil, and the MASW method utilized here is capable of providing reasonable results to that depth.

\section{Appendices}

\section{A. Wavefield Transformation Method}

Construction and extraction of the dispersion curves is an important part of the MASW method. The wavefield transformation method (McMechan and Yedlin [24]; Park et al. [25]), summarized in the following steps, is used to construct the dispersion curves:

(1) The fast Fourier transform (FFT) is applied on shot gather record, $U(x, t)$, where $x$ and $t$ are distance and time, respectively.

(2) The Fourier transform obtained in the frequency $(\omega)$ domain, $U(x, \omega)$, is the product of the phase function, $P(x, \omega)$, and the amplitude function, $A(x, \omega)$, that is:

$$
U(x, \omega)=P(x, \omega) * A(x, \omega)
$$

(3) The phase function, $P(x, \omega)$, is expressed in the following form:

$$
P(x, \omega)=e^{-i \Phi x},
$$

where $\Phi=\omega / C$ and $C$ is the phase velocity, which means $P(x, \omega)$ contains the dispersion property information.
(4) The following transform is then applied to $P(x, \omega)$ :

$$
\begin{aligned}
& V(\omega)=\int e^{-i \varphi x}\left[\frac{U(x, \omega)}{|U(x, \omega)|}\right] d x, \text { or } \\
& V(\omega)=\int e^{-i(\Phi-\varphi) x}\left[\frac{A(x, \omega)}{|A(x, \omega)|}\right] d x,
\end{aligned}
$$

where $\varphi$ is the parameter in this transform. The maximum value of $V(\omega)$ occurs when $\Phi=\varphi=\omega / C$ and, hence, the locus of the peaks of $V(\omega)$ for the different values of $\omega$ yields the image of the dispersion curve. Thus, $V(\omega)$, which shows the summation over offset of wavefield with offset-dependent phase shift, provides the dispersion curve.

\section{B. Generalized Inversion Technique}

In linear inversion, the relation between the observed phase velocity matrix $(f)$ and model parameters matrix $(x)$, which are the shear wave velocities of the layers, is expressed by the following form:

$$
x=G^{-1} f,
$$

where $G$ is the model matrix.

In contrast, it is assumed in the non-linear inversion approach that the variation of the observed phase velocity, $\Delta f$, is proportional to the variation of model parameters, $\Delta x$, (shear wave velocity in our case) that is:

$$
\Delta x=G^{-1} \Delta f
$$

For a variable function of $f(x)$, which is differentiable at least $n$ times from the points $x$ to $x+\delta x$, the Taylor expansion can be written:

$$
f(x+\delta x)=f(x)+g^{T} \delta x+0.5 \delta x^{T} H \delta x+\cdots,
$$

where $g^{T}$ is the transpose of the gradient vector and $H$ is the Hessian matrix.

Levenberg and Marquardt (Marquardt [36]) consider both of the introduced terms $\left(g^{T} \delta x\right.$ and $\left.0.5 \delta x^{T} H \delta x\right)$. Knowing that $f(x+\delta x)-f(x)=\Delta f$, using (B.5) and (B.6) and also applying the least squares method, the $G^{-1}$ is:

$$
G^{-1}=\frac{\Delta x}{(f(x+\delta x)-f(x))}=-\left[A^{T} A+\lambda I\right]^{-1} A^{T},
$$

where $A$ is a Jacobian matrix containing the partial derivatives of $\Delta f$ relative to $\Delta x$, and $\lambda$ is the eigenvalues of the matrix $A^{T} A$ (Lee and Stewart [46]). 
So the inversion algorithm can be implemented, $\Delta x$ is obtained using (B.5) and (B.7), knowing that $\Delta f=f_{\text {observed }}-$ $f_{\text {model }}$, where $f_{\text {observed }}$ is the phase velocity in the extracted dispersion curve, and $f_{\text {model }}$ is the phase velocity obtained from the model using the method introduced by Schwab and Knopoff [34]. $f_{\text {model }}$ is a function of $x$ (shear wave velocity), and a suitable initial profile is needed to start the inverse algorithm. A new $x$ (where $x_{\text {new }}=x_{\text {previous }}+\Delta x$ ), which is the shear wave velocity profile, is updated in each step until the desired least squares errors are obtained.

\section{Acknowledgments}

The authors thank Natural Sciences and Engineering Research Council of Canada (NSERC), the Ontario Research and Development Challenge Fund (ORDCF) and Portable Observatories for Lithospheric Analysis and Research Investigating Seismicity (POLARIS) for their financial and technical support. Funding for this work also came from the Eastern Canada Hazards Project (G. Brooks, project leader) of the Geological Survey of Canada. They wish to thank S. E. Pullan, J. A. Hunter, A. Pugin, T. Cartwright, R. A. Burns, R. L. Good, and M. Douma from the Geological Survey of Canada, for their comments and assistance and Carleton University students, A. Duxbury and V. Ter-Emmanuilyan.

\section{References}

[1] J. Adams and S. Halchuck, "A review of NBCC 2005 seismic hazard results for Canada-the interface to the ground and prognosis for urban risk mitigation," in Proceedings of the 57th Canadian Geotechnical Conference, pp. 1-9, Quebec, Canada, October 2004.

[2] NBC, "National Building Code of Canada," Canadian commission on building and fire codes, National Research Council Canada, 2005.

[3] Natural Resources Canada online maps, "Urban Geology of NCR (Surficial Boreholes)," Copyright of the Geological Survey of Canada, 2006, http://tsdmaps.gsc.nrcan.nrcan .gc.ca/website/_urbgeo_natcap/surficial_boreholes_e.htm.

[4] D. Motazedian and J. Hunter, "Development of an NEHRP map for the Orleans suburb of Ottawa, Ontario," Canadian Geotechnical Journal, vol. 45, no. 8, pp. 1180-1188, 2008.

[5] "GSC preliminary map of Holocene thickness for the Orleans area," Geological Survey of Canada, 2007.

[6] F. Tallavó, G. Cascante, and M. Pandey, "Experimental and numerical analysis of MASW tests for detection of buried timber trestles," Soil Dynamics and Earthquake Engineering, vol. 29, no. 1, pp. 91-102, 2009.

[7] A. Nasseri-Moghaddam, G. Cascante, C. Phillips, and D. J. Hutchinson, "Effects of underground cavities on Rayleigh waves-Field and numerical experiments," Soil Dynamics and Earthquake Engineering, vol. 27, no. 4, pp. 300-313, 2007.

[8] C. Xu and S. D. Butt, "Evaluation of MASW techniques to image steeply dipping cavities in laterally inhomogeneous terrain," Journal of Applied Geophysics, vol. 59, no. 2, pp. 106116, 2006.

[9] G. Cascante, H. Najjaran, and P. Crespi, "Novel methodology for nondestructive evaluation of brick walls: fuzzy logic analysis of MASW tests," Journal of Infrastructure Systems, vol. 14, no. 2, pp. 117-128, 2008.
[10] A. I. Kanl, P. Tildy, Z. Prónay, A. Pinar, and L. Hermann, " $V_{s}{ }^{30}$ mapping and soil classification for seismic site effect evaluation in Dinar region, SW Turkey," Geophysical Journal International, vol. 165, no. 1, pp. 223-235, 2006.

[11] J. S. Heisey, K. H. Stokoe II, W. R. Hudson, and A. H. Meyer, "Determination of in-situ shear wave velocities from spectral analysis of surface waves," Research Report 256-2, Center for Transportation Research, The University of Texas at Austin, 1982.

[12] S. Nazarian, K. H. Stokoe II, and W. R. Hudson, "Use of spectral analysis of surface waves method for determination of moduli and thicknesses of pavement systems," Transportation Research Record, pp. 38-45, 1983.

[13] S. Nazarian, In situ determination of elastic moduli of soil deposits and pavement systems by spectral-analysis-of-surfacewaves method, Ph.D. dissertation, University of Texas at Austin, Austin, Tex, USA, 1984.

[14] D. Crice, "MASW, the wave of the future," Journal of Environmental and Engineering Geophysics, vol. 10, no. 2, pp. 77-79, 2005.

[15] F. E. Richart, J. R. Hall, and R. D. Woods, Vibrations of Soils and Foundations, Prentice-Hall, Englewood Cliffs, NJ, USA, 1970.

[16] C.-P. Lin, C.-C. Chang, and T.-S. Chang, "The use of MASW method in the assessment of soil liquefaction potential," Soil Dynamics and Earthquake Engineering, vol. 24, no. 9-10, pp. 689-698, 2004.

[17] J. Xia, C. Chen, P. H. Li, and M. J. Lewis, "Delineation of a collapse feature in a noisy environment using a multi-channel surface wave technique," Geotechnique, vol. 54, no. 1, pp. 1727, 2004.

[18] C. B. Park and R. D. Miller, "Roadside passive multi-channel analysis of surface waves (MASW)," Journal of Environmental and Engineering Geophysics, vol. 13, no. 1, pp. 1-11, 2008.

[19] C. B. Park, R. D. Miller, N. Ryden, J. Xia, and J. Ivanov, "Combined use of active and passive surface waves," Journal of Environmental and Engineering Geophysics, vol. 10, no. 3, pp. 323-334, 2005.

[20] J. N. Louie, "Faster, better: shear-wave velocity to 100 meters depth from refraction microtremor arrays," Bulletin of the Seismological Society of America, vol. 91, no. 2, pp. 347-364, 2001.

[21] H. Okada, The Microtremor Survey Method, Geophysical Monograph Series, no.12, Society of Exploration Geophysicists, 2003.

[22] W. Heukelom and C. R. Foster, "Dynamic testing of pavements," Journal of Soil Mechanics and Foundation Division, 1960, ASCE, 86, Part I.

[23] R. Jones, "Surface wave technique for measuring the elastic properties and thickness of roads: theoretical development," British Journal of Applied Physics, vol. 13, no. 1, pp. 21-29, 1962.

[24] G. A. McMechan and M. J. Yedlin, "Analysis of dispersive waves by wave field transformation," Geophysics, vol. 46, no. 6, pp. 869-874, 1981.

[25] C. B. Park, R. D. Miller, and J. Xia, "Imaging dispersion curves of surface waves on multi-channel record," in 68th Annual Meeting of the Society of Exploration Geophysicists, pp. 13771380, New Orleans, La, USA, 1998.

[26] D. J. Zywicki and G. J. Rix, "Frequency-wavenumber analysis of passive surface waves," in Proceedings of the Symposium on the Application of Geophysics to Environmental and Engineering Problems (SAGEEP' '99), pp. 75-84, 1999. 
[27] K. K. Ashiya, O. Yoshioka, and H. Yokoyama, "Estimation of phase velocities of multiple modes by inversion of frequencywave number spectrum and its application to train induced ground vibrations," Geophysical Exploration Journal, vol. 52, no. 3, pp. 214-226, 1999.

[28] S. X. Zhang, L. S. Chan, C. Y. Chen, F. C. Dai, X. K. Shen, and H. Zhong, "Apparent phase velocities and fundamentalmode phase velocities of Rayleigh waves," Soil Dynamics and Earthquake Engineering, vol. 23, no. 7, pp. 563-569, 2003.

[29] Y. Luo, J. Xia, J. Liu, Y. Xu, and Q. Liu, "Research on the middle-of-receiver-spread assumption of the MASW method," Soil Dynamics and Earthquake Engineering, vol. 29, no. 1, pp. 71-79, 2009.

[30] N. Ryden and C. B. Park, "Fast simulated annealing inversion of surface waves on pavement using phase-velocity spectra," Geophysics, vol. 71, no. 4, pp. R49-R58, 2006.

[31] H. Szu and R. Hartley, "Fast simulated annealing," Physics Letters A, vol. 122, no. 3-4, pp. 157-162, 1987.

[32] S. X. Zhang and L. S. Chan, "Possible effects of misidentified mode number on Rayleigh wave inversion," Journal of Applied Geophysics, vol. 53, no. 1, pp. 17-29, 2003.

[33] C. B. Park, "Surfseis software for active and passive MASW," Kansas geological survey, 2004.

[34] F. Schwab and L. Knopoff, "Fast surface wave and free mode computations," in Methods in Computational Physics, vol. 11, pp. 87-180, Academic Press, New York, NY, USA, 1972.

[35] J. Xia, R. D. Miller, and C. B. Park, "Estimation of nearsurface shear-wave velocity by inversion of Rayleigh waves," Geophysics, vol. 64, no. 3, pp. 691-700, 1999.

[36] D. W. Marquardt, "An algorithm for least-squares estimation of nonlinear parameters," Journal of the Society for Industrial and Applied Mathematics, vol. 11, pp. 431-441, 1963.

[37] G. H. Golub and C. Reinsch, "Singular value decomposition and least squares solutions," Numerische Mathematik, vol. 14, no. 5, pp. 403-420, 1970.

[38] J. Xia, R. D. Miller, C. B. Park, J. A. Hunter, J. B. Harris, and J. Ivanov, "Comparing shear-wave velocity profiles inverted from multi-channel surface wave with borehole measurements," Soil Dynamics and Earthquake Engineering, vol. 22, no. 3, pp. 181-190, 2002.

[39] J. A. Hunter, R. A. Burns, R. L. Good, and C. F. Pelletier, "A compilation of shear wave velocities and borehole geophysical logs in unconsolidated sediments of the Fraser River delta," Geological Survey of Canada, Open File No. 3622, 1998.

[40] M. Long and S. Donohue, "In situ shear wave velocity from multi-channel analysis of surface waves (MASW) tests at eight Norwegian research sites," Canadian Geotechnical Journal, vol. 44, no. 5, pp. 533-544, 2007.

[41] S. M. Richwalski, M. Picozzi, S. Parolai et al., "Rayleigh wave dispersion curves from seismological and engineeringgeotechnical methods: a comparison at the Bornheim test site (Germany)," Journal of Geophysics and Engineering, vol. 4, no. 4, pp. 349-361, 2007.

[42] T. Thitimakorn, N. L. Anderson, R. Stephenson, and W. Liu, 2D Shear Wave Velocity Profile Along Test Segment of Interstate I70, Site Characterization and Modeling, ASCE, St. Louis, Mo, USA, 2005.

[43] D. Hoffman, R. W. Stephenson, R. Luna, and N. L. Anderson, "Non-destructive testing of earthquake hazard mapping, Southern Missouri, USA," in Ground Modification and Seismic Mitigation, pp. 433-440, ASCE, 2006.
[44] D. W. Casto, B. Luke, C. Calderón-Macías, and R. Kaufmann, "Interpreting surface-wave data for a site with shallow bedrock," Journal of Environmental and Engineering Geophysics, vol. 14, no. 3, pp. 115-127, 2009.

[45] D. W. Casto, C. Calderón-Macías, B. Luke, and R. Kaufmann, "Improving MASW results for a site with shallow bedrock through the use of higher-mode data," in Proceedings of GeoFlorida, West Palm Beach, Fla, USA, 2010.

[46] W. H. K. Lee and S. W. Stewart, "Generalized Inversion and Nonlinear Optimization section," in Principles and Applications of Microeathquake Networks, pp. 105-128, Academic Press, New York, NY, USA, 1981. 

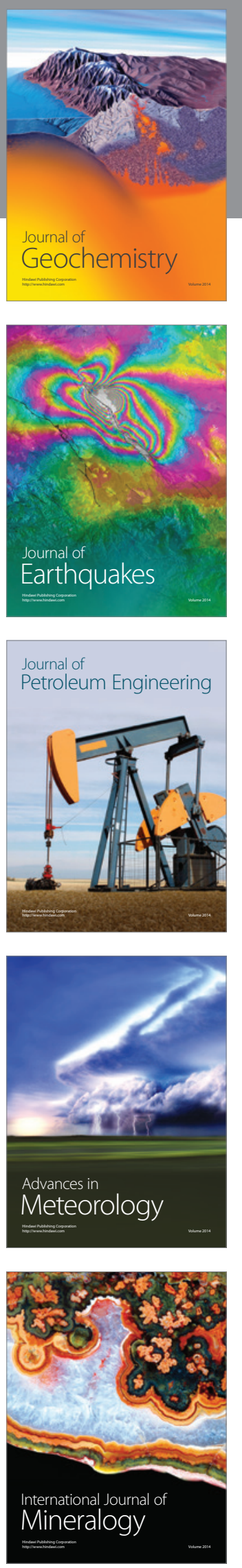
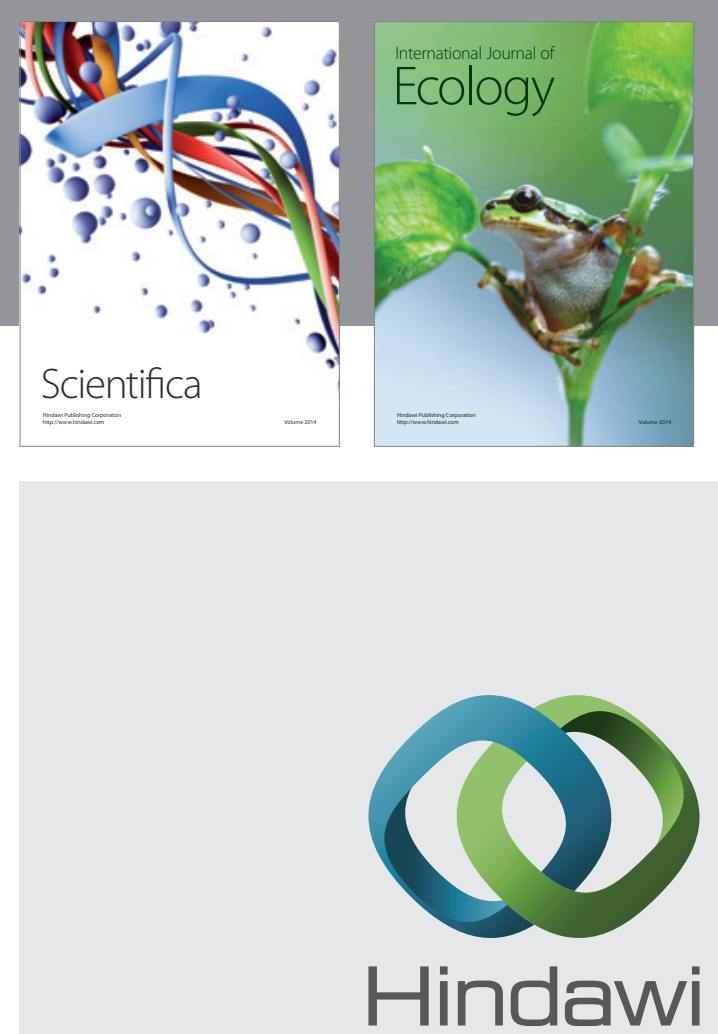

Submit your manuscripts at http://www.hindawi.com
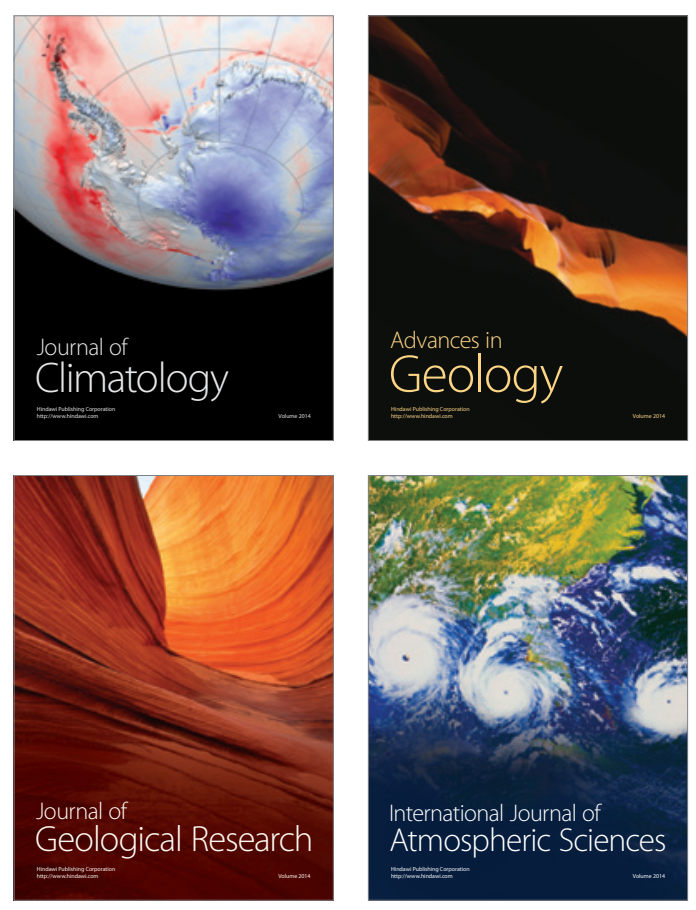
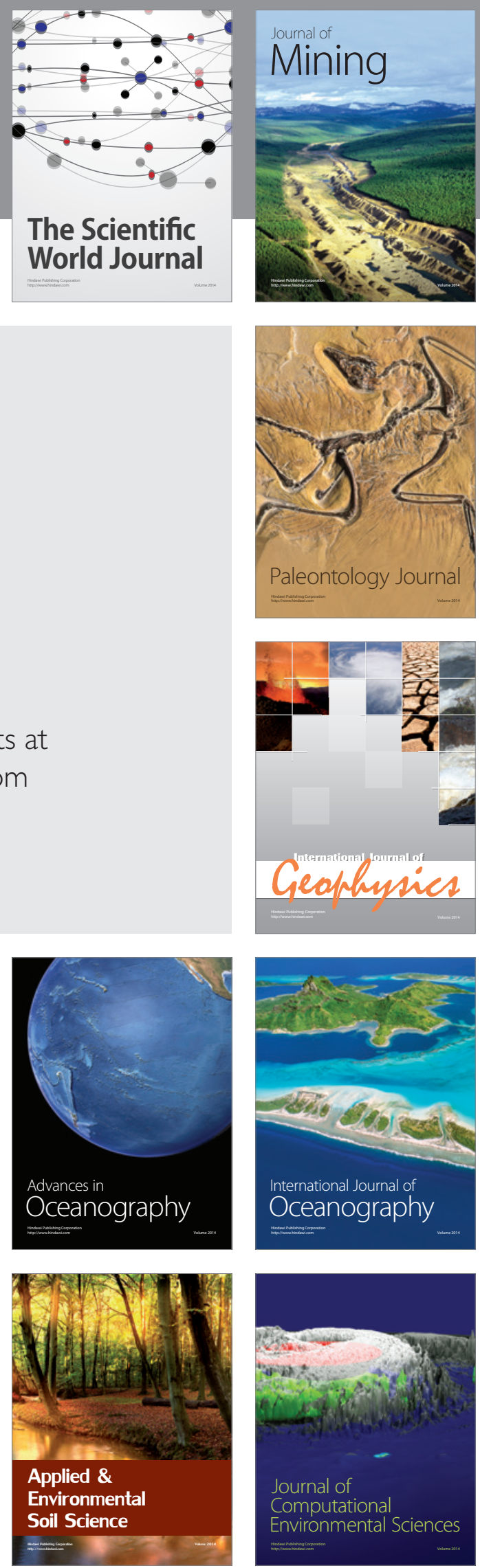